\title{
Clindamycin for acute osteomyelitis in children
}

\author{
M. R. WHARTON \\ M.B., M.Ch.(Orth.), F.R.C.S.
}

\author{
F. H. BEDDOW \\ M.Ch.(Orth.), F.R.C.S.
}

\author{
Alder Hey Hospital, Liverpool and Whiston Hospital, Prescot
}

\begin{abstract}
Summary
A series of thirty-five children with acute haematogenous osteomyelitis who received clindamycin as the antibiotic of choice is described. Successful primary healing was achieved in thirty-three patients. The advantages of operation when indicated are discussed in relation to bacteriological identification.
\end{abstract}

\section{Introduction}

Clindamycin is an antibiotic with high bacteriostatic and bacteriocidal activity against Staphylococcus aureus (Myers et al., 1969). Oral administration is an advantage when treatment for up to 6 weeks may be desirable. Bone penetration by clindamycin is extremely good (Vacek et al., 1972). During the 4 years that clindamycin has been available there have been two reports of a strain of Staph. aureus resistant to this drug (Thompson, 1972; Chattopadhyay and Kohn, 1972).

Its use in osteomyelitis has been reported by Geddes et al. (1970) when six of seven patients responded satisfactorily. A further paper (Mitchell and Garden, 1972) reported nine patients all responding well to clindamycin. The series of Kosmidis et al. (1973) contained eight patients with acute osteomyelitis, all resolving fully.

Clindamycin was introduced for the treatment of acute osteomyelitis at Whiston Hospital, Liverpool, in 1970 and at the adjacent Alder Hey Children's Hospital in 1971. This paper reports the results obtained in patients treated during the 3 years 19701972 inclusive.

\section{Outline of management}

All patients had typical clinical features of acute haematogenous osteomyelitis. They all developed radiological changes which helped to confirm the diagnosis. Blood was taken for culture, cell counts and ESR determination and radiographs were obtained before definitive treatment was started. Suitable splintage was applied to rest the affected part. Operation with primary wound closure was undertaken if it was considered that pus could be present, this being generally within $48 \mathrm{hr}$ of admission. Where

Correspondence: Mr M. R. Wharton, Senior Registrar in Orthopaedic Surgery, Preston Royal Infirmary, Preston, Lancs. operation was performed, the opportunity was taken to obtain a swab for bacteriological control.

Clindamycin was given four times daily, each dose being $75 \mathrm{mg}$ for patients up to 7 years and $150 \mathrm{mg}$ over that age. In the earlier part of the series, children received clindamycin for 6 weeks, except for two who received it for 2 months each. In the final 6 months of the series it was decided that clindamycin therapy for only 4 weeks was sufficient.

\section{Analysis of patients}

Thirty-five patients were included in the study, their ages ranging from 5 to 15 years. Nineteen were boys and sixteen were girls. The sites involved were as follows: femur, 13; tibia, 11; fibula, 5 ; metatarsal, 3 ; radius, 2 ; humerus, 1 ; pelvis (ilium), 1; os calcis, 1 ; clavicle, 1 ; finger phalanx, 1 .

One patient had four sites of disease (left upper femur and upper tibia, right lower femur and lower tibia) and one patient had two sites (right lower femur and left lower tibia).

The average duration of symptoms before referral to hospital was 4 days. Thirteen patients had received an antibiotic other than clindamycin without clinical improvement before admission. The remaining twenty-two patients had received no prior antibiotic therapy.

Operative treatment was performed in thirty-one patients with release of pus in thirty.

\section{Bacteriology}

Staph. aureus was cultured from the blood in only seven patients. An organism was isolated from the pus released at operation in twenty-eight patients.

TABle 1. Bacteriology

\begin{tabular}{lr}
\hline Total number of patients & 35 \\
Positive blood cultures yielding Staph. aureus & 7 \\
Number of operations performed & 31 \\
Number with pus present at operation & 30 \\
Organisms isolated from pus & \\
Staphylococcus albus & 1 \\
Staph. aureus + Strep. faecalis & 26 \\
Staph. aureus alone & 28 \\
& Total \\
Number of isolates of Staph. aureus sensitive & \\
to penicillin & 5 \\
\hline
\end{tabular}


Of the three not yielding organisms from wound swabs, only one had previously received an antibiotic. In the four patients not explored, blood culture was positive in only one. A pure culture of Staph. albus was isolated from the pus of one patient. In another, Streptococcus faecalis was present together with Staph. aureus. In the remainder, the infecting organism was Staph. aureus alone.

The Staphylococcus was sensitive to penicillin in only five instances. In two of these, penicillin had been given without controlling symptoms before referral to hospital. One Staphylococcus sp. was resistant to tetracycline but no resistance to fusidic acid, erythromycin, cloxacillin or clindamycin was demonstrated.

\section{Results of treatment}

We have used the definition of Blockey and Watson (1970) where primary treatment is regarded as successful if symptoms and clinical signs have disappeared within 4 weeks of admission and no infective complications resulting from local bone disease develop subsequently. In our experience, however, most patients were without clinical evidence of osteomyelitis in a much shorter time. Of the thirty-five patients in the series, thirty-three healed primarily. The two primary failures each received operative exploration and are detailed as follows.

(1) A 15-year-old girl with a history suggesting osteomyelitis of the upper end of the right femur of 3 days' duration had received an ampicillin/cloxacillin combination for 2 days before admission. When first seen her general condition was toxic. Staph. aureus was isolated from the blood and clindamycin was given for 6 weeks. No pus was found at operation but subsequent radiographs showed a definite periosteal reaction. Although appearing to resolve primarily, 4 months later an area of cellulitis appeared around the healed wound. Ampicillin was given for this elsewhere and the condition rapidly subsided. A radiograph at this time was normal. Six months later there was no evidence of reactivation either clinically or radiologically.

(2) A 14-year-old boy, the first in the series, had a 6-day history relating to the right lower femur and left lower tibia. Pus yielding Staph. aureus resistant to penicillin was drained from both sites. Blood culture was negative. Clindamycin was not started here until the bacteriological report was available. The femoral wound healed primarily but the tibial wound was slow to heal, taking 10 weeks. There had been no recurrence at review 3 years later.

The patients were seen at intervals, and reviewed finally at periods from 6 months to 3 years following completion of treatment. All thirty-five patients thus healed eventually and apart from the first of the two primary failures described above there was no recurrence. No complications or side effects were recorded which could have been attributable to clindamycin and there was no evidence that any staphylococci developed resistance to this antibiotic.

There were two instances of disturbance of bone growth, one in a first metatarsal resulting in a short hallux, and one in a finger phalanx.

Radiographs at review showed no examples of Brodie's abscess but occasionally revealed trabecular irregularity or slight thickening.

\section{Discussion}

The proportion of patients with primary healing in this series of children with proven acute osteomyelitis was thirty-three of thirty-five $(94.3 \%)$. This compares with ninety-two of $113(81.4 \%)$ in the series of Blockey and Watson (1970) where a combination of penicillin and cloxacillin was used and thirty-four of thirty-eight $(89.5 \%)$ in the later series of Blockey and McAllister (1972) where an erythromycin-fusidic acid combination was used.

A decision to operate was made when it was thought that pus could reasonably be expected to be found. The operation rate in the present series was $89 \%$ as opposed to $50 \%$ in that of Blockey and Watson (1970). The high operation rate in this series may be related to the duration of infection before presentation at hospital.

For conservative treatment to be successful, the diagnosis must be made early and therapy started promptly before a significant collection of pus has had time to form. There is no doubt that surgery provides the best opportunity for obtaining the organism for bacterial identification, sensitivity pattern and the control of antibiotic therapy.

Experience with clindamycin as the antibiotic of choice in acute haematogenous osteomyelitis indicates that results compare favourably with those where other antibiotics, either single or in combination, were used.

\section{Acknowledgments}

We are indebted to Mr Shatwell, Mr F. C. Dwyer and $\mathrm{Mr}$ R. Owen for permission to publish details of their patients at Alder Hey Hospital.

Requests for reprints should be addressed to $\mathrm{Mr}$ M. R. Wharton, Preston Royal Infirmary, Preston, Lancs.

\section{References}

Blockey, N.J. \& MCAllister, T.A. (1972) Antibiotics in acute osteomyelitis in children. Journal of Bone and Joint Surgery, 54B, 299.

Blockey, N.J. \& Watson, J.T. (1970) Acute osteomyelitis in children. Journal of Bone and Joint Surgery, 52B, 77.

Chattopadhyay, B. \& Kohn, J. (1972) The treatment of multiple-resistant Staphylococcus aureus infection. Clinical Trials Journal, 9, 17. 
Geddes, A.M., Bridgwater, F.A.J., Williams, D.N., Oon, J. \& GrimshaW, G.J. (1970) Clinical and bacteriological studies with clindamycin. British Medical Journal, ii, 703.

Kosmidis, J.C., Corbett, V., Cole, A.J.L., Finch, R.G., BARKER, J.E. \& GedDES, A.M. (1973) The treatment of paediatric infections with the lincomycins. British Journal of Clinical Practice, 27, No. 8, 315.

Mitchell, A.A.B. \& Garden, J. (1972) The treatment of staphylococcal infections. Clinical Trials Journal, 9, 11.
Myers, B.R., Kaplan, K. \& Weinstein, L. (1969) Microbiological and pharmacological behaviour of 7-chlorolincomycin. Applied Microbiology, 17, 653.

ThompSon, R.E.M. (1972) Routine isolates of Staphylococcus aureus and other Gram-positive organisms. Clinical Trials Journal, 9, 7.

Vacek, V., Hejzlar, M., Slavik, M. \& Pavlansky, R. (1972) Penetration of clindamycin into bone in man. Chemotherapy, 17, 22. 